\title{
Recent declines in breast cancer incidence: mounting evidence that reduced use of menopausal hormones is largely responsible
}

\author{
Emily Banks*1 and Karen Canfell2,3 \\ See related research article by Marshall et al., http://breast-cancer-research.com/content/12/1/R4
}

\begin{abstract}
Substantial reductions in breast cancer incidence in women 50 years old or older have been observed recently in many developed countries, and falling use of menopausal hormone therapy $(\mathrm{HT})$ remains the most plausible explanation. In keeping with recent observations from the Women's Health Initiative, a report from the California Teachers Study cohort in this issue of Breast Cancer Research adds to this growing evidence. The investigators found a $26 \%$ reduction in invasive breast cancer in the cohort from 2000-2002 to 2003-2005, which accompanied an estimated 64\% drop in HT use between 2000-2001 and 2005-2006. By collating individual data on the use of HT and breast cancer incidence, they also demonstrated that the decline in incidence was concentrated in women who had ceased HT use. The decline reflected a decrease predominantly in oestrogen receptor-positive tumours in the context of stable screening patterns over the study period. Millions of women continue to use HT, and these findings support carefully targeted shortduration use as an important ongoing strategy to minimise breast cancer risk.
\end{abstract}

\section{The findings of the California Teachers Study}

The report from the California Teachers Study cohort [1] in this issue of Breast Cancer Research adds to the mounting evidence that reductions in the use of menopausal hormone therapy (HT) are largely responsible for the recent declines in breast cancer that have been

*Correspondence: emily.banks@anu.edu.au

'National Centre for Epidemiology and Population Health, The Australian National University, Canberra, ACT, 0200 Australia

Full list of author information is available at the end of the article observed in many countries in women 50 years old or older [2-4]. The study followed 74,647 female teachers and administrators from public schools; the women included in this analysis were 50 years old or older and were recruited to the study in 1995-1996 [1]. A total of 2,668 incident invasive and 565 in situ breast cancers were diagnosed in the cohort [1]. The prevalence of HT use at baseline was extremely high, with around $60 \%$ of women reporting current use. HT use was updated in 2000-2001, with illustrative data in 2005-2006 available for a subset of the cohort.

The investigators found a $26 \%$ reduction in invasive breast cancer in the cohort from 2000-2002 to 2003-2005 [1]. This accompanied an estimated 64\% drop in HT use between 2000-2001 (58\% current HT use) and 2005-2006 (21\% current HT use) following publication of the main results of the Women's Health Initiative (WHI) trial [1,5]. By collating individual data on the use of HT and breast cancer incidence, they demonstrated that the decline in incidence was concentrated in women who had ceased HT use. The decline was greater in prior users of oestrogenprogestagen HT (47\% decline; $P<0.001$ ) than in oestrogenonly HT ( $26 \%$ decline; $P=0.01$ ) but was substantial and significant in both groups and reflected a decrease predominantly in oestrogen receptor-positive tumours [1]. Almost $97 \%$ of the cohort reported mammographic screening according to recommended guidelines, and rates of in situ cancers remained stable, indicating consistent screening patterns over the period [1].

\section{The plausibility of a rapid drop in breast cancer incidence following cessation of use of menopausal hormone therapy}

It is now clear that breast cancer risk is elevated in women using HT [6]; ecological [2,3] and observational $[7,8]$ studies show that this elevated risk declines rapidly following cessation of use. The follow-up data from the California Teachers Study cohort build on the recently published analyses of the WHI trial and its associated 
observational cohort study [9]. These analyses demonstrated rapid reductions in breast cancer incidence following cessation of combined HT; in the WHI observational cohort, breast cancer incidence declined by $43 \%$ from 2002 to 2003 in women who had ceased use of HRT [9]. Because these cohort studies were large enough to identify statistically significant falls in breast cancer incidence from 2002 onwards, they confirm the ecological studies' findings [1,9]; and because both studies collated individual-level information on HT use, they have additionally confirmed that the declines in breast cancer occurred in women who had ceased HT [1,9].

The greater breast cancer decline in former users of oestrogen-progestagen versus oestrogen-only HT observed in the California Teachers Study is consistent with prior data on the magnitude of the risks associated with each $[6,8]$; and the fact that the decline was observed predominantly in oestrogen receptor-positive tumours is consistent with the emerging evidence that HT particularly increases the risk of oestrogen receptor-positive breast cancer $[10,11]$. Furthermore, the rapidity of the decline in breast cancer with HT cessation is in keeping with the historical precedents of declining endometrial cancer following reductions in oestrogen-only HT in the 1970s [12] and rapid reductions in lung cancer risk following smoking cessation [13].

\section{Current drug regulations and patterns of use}

There is broad consensus in the guidance issued by drug regulatory authorities in the UK, US, Europe and Australia in recommending that HT be used only for treatment of moderate to severe menopausal symptoms, for as short a time as possible, and not generally for the first-line prevention of osteoporosis or other chronic disease [14].

The risks of use of HT, particularly prolonged use, are not trivial. The most recent independent quantitative review of the evidence finds that 5 years of use of combined HT among women in their fifties leads to the development of an excess potentially life-threatening condition attributable to HT among $1.4 \%$ of users; that is, net excess cases of breast cancer, stroke, ovarian cancer, endometrial cancer or venous thromboembolism that are not offset by reduced hip fracture or colorectal cancer incidence (number needed to harm $=71$ ) [6]. This rises to $4.0 \%$ (number needed to harm $=25$ ) with 10 years of use. The corresponding figures for oestrogen-only HT use in women in their fifties without a uterus are $0.5 \%$ for 5 years of use and $1.2 \%$ for 10 years of use [6]. The overall absolute risks related to $\mathrm{HT}$ are dependent on whether an oestrogen-progestagen or oestrogen-only preparation is used, the duration of use, a woman's age and body mass index and her background risk of the relevant conditions. The most comprehensive analyses to date do not support the 'timing hypothesis'; hence, the relative risks and benefits are not influenced significantly by the time between menopause and commencing use [15].

In keeping with other US findings [2], the reduction in HT use in the California Teachers Study cohort from 2002 onwards was dramatic. Population-wide reductions in breast cancer have been widely attributed to more cautious and targeted use of HT [4]. Yet $21 \%$ of the California Teachers Study cohort were current HT users in the 2005-2006 resurvey, highlighting the fact that large numbers of women continue to use HT. The optimal prevalence of HT is not known. However, use should predominantly be short-term and should reflect both the prevalence of moderate to severe menopausal symptoms and the proportion of well-informed women who choose to use HT as treatment for these symptoms after due consideration of its risks and benefits.

\section{Abbreviations}

$\mathrm{HT}=$ hormone therapy; WHI = Women's Health Initiative.

\section{Author details}

'National Centre for Epidemiology and Population Health, The Australian National University, Canberra, ACT, 0200 Australia

${ }^{2}$ Cancer Epidemiology Research Unit, The Cancer Council New South Wales, Sydney, 153 Dowling Street, Woolloomooloo, NSW 2011 Australia

${ }^{3}$ School of Public Health, The University of Sydney, Sydney NSW 2006, Australia

\section{Competing interests}

The authors declare that they have no competing interests.

Published: 12 February 2010

\section{References}

1. Marshall SF, Clarke CA, Deapen D, DeLellis Henderson K, Largent Neuhausen SL, Reynolds P, Ursin G, Horn-Ross PL, Stram DO, Templeman C, Bernstein L: Recent breast cancer incidence trends according to hormone therapy use: the California Teachers Study cohort. Breast Cancer Res 2010, 12:R4.

2. Ravdin PM, Cronin KA, Howlader N, Berg CD, Chlebowski RT, Feuer EJ, Edwards BK, Berry DA: The decrease in breast-cancer incidence in 2003 in the United States. N Engl J Med 2007, 356:1670-1674.

3. Canfell K, Banks E, Moa A, Beral V: Decrease in breast cancer incidence following a rapid fall in use of hormone replacement therapy in Australia. Med J Aust 2008, 188:641-644.

4. Kumle M: Declining breast cancer incidence and decreased HRT use. Lancet 2008, 372:608-610.

5. Writing Group for the Women's Health Initiative Investigators: Risks and benefits of estrogen plus progestin in healthy postmenopausal women. JAMA 2002, 288:321-333.

6. Medicines and Healthcare Products Regulatory Agency: UK Public Assessment Report. Hormone-replacement therapy: safety update. London: Medicines and Healthcare Products Regulatory Agency; 2007 [http://www.mhra.gov.uk/home/groups/pl-p/documents/websiteresources/ con2032228.pdf].

7. Collaborative Group on Hormonal Factors in Breast Cancer: Breast cancer and hormone replacement therapy: collaborative reanalysis of data from 51 epidemiological studies of 52705 women with breast cancer and 108 411 women without breast cancer. Lancet 1997, 350:1047-1059.

8. Million Women Study Collaborators: Breast cancer and hormonereplacement therapy in the Million Women Study. Lancet 2003, 362:419-427.

9. Chlebowski RT, Kuller LH, Prentice RL, Stefanick ML, Manson JE, Gass M, Aragaki AK, Ockene JK, Lane DS, Sarto GE, Rajkovic A, Schenken R, Hendrix SL, Ravdin PM, Rohan TE, Yasmeen S, Anderson G; WHI Investigators: Breast cancer after use of estrogen plus progestin in postmenopausal women. 
N Engl J Med 2009, 360:573-587.

10. Brinton LA, Richesson D, Leitzmann MF, Gierach GL, Schatzkin A, Mouw T, Hollenbeck AR, Lacey JV Jr:: Menopausal hormone therapy and breast cancer risk in the NIH-AARP Diet and Health Cohort Study. Cancer Epidemiol Biomarkers Prev 2008, 17:3150-3160.

11. Stahlberg C, Pedersen AT, Andersen ZJ, Keiding N, Hundrup YA, Obel EB, Møller S, Rank F, Ottesen B, Lynge E: Breast cancer with different prognostic characteristics developing in Danish women using hormone replacement therapy. Br J Cancer 2004, 91:644-650

12. Austin DF, Roe FJ: The decreasing incidence of endometrial cancer: public health implications. Am J Public Health 1982, 72:65-68.

13. Peto R, Darby S, Deo H, Silcocks P, Whitley E, Doll R: Smoking, smoking cessation, and lung cancer in the UK since 1950: combination of national statistics with two case-control studies. BMJ 2000, 321:323-329.
14. Banks E, Canfell K: Invited commentary: hormone therapy risks and benefits-the Women's Health Initiative findings and the postmenopausal estrogen timing hypothesis. Am J Epidemiol 2009, 174:24-28.

15. Prentice RL, Manson JE, Langer RD, Anderson GL, Pettinger M, Jackson RD, Johnson KC, Kuller LH, Lane DS, Wactawski-Wende J, Brzyski R, Allison M, Ockene J, Sarto G, Rossouw JE: Benefits and risks of postmenopausal hormone therapy when initiated soon after then menopause. Am J Epidemiol 2009, 170:12-23.

doi:10.1186/bcr2463

Cite this article as: Banks E, Canfell K: Recent declines in breast cancer incidence: mounting evidence that reduced use of menopausal hormones is largely responsible. Breast Cancer Research 2010, 12:103. 